\title{
Dynamic Mechanical Response and Dissipated Energy Analysis of Sandstone under Freeze-Thaw Cycles
}

\author{
Ke Man $\mathbb{D}^{1},{ }^{1}$ Zongxu Liu, ${ }^{1}$ Zhifei Song $\mathbb{D}^{1},{ }^{1}$ and Xiaoli Liu ${ }^{2}$ \\ ${ }^{1}$ School of Civil Engineering, North China University of Technology, Beijing 100144, China \\ ${ }^{2}$ State Key Laboratory of Hydro Science and Hydraulic Engineering, Tsinghua University, Beijing 100084, China \\ Correspondence should be addressed to Zhifei Song; song59672@163.com
}

Received 24 August 2021; Accepted 22 October 2021; Published 10 November 2021

Academic Editor: Yu Wang

Copyright ( 2021 Ke Man et al. This is an open access article distributed under the Creative Commons Attribution License, which permits unrestricted use, distribution, and reproduction in any medium, provided the original work is properly cited.

\begin{abstract}
Based on the sandstone from the slope of Baorixile open-pit mining area in Hulunbuir City, Inner Mongolia, the dynamic uniaxial compression test of sandstone with different freeze-thaw cycles has been carried out by Split Hopkinson Pressure Bar test (SHPB). The test results show that the crushing degree of sandstone becomes serious with the freeze-thaw cycle times and strain rate increases. The dynamic compressive strength increases with the raise of strain rate under the same freeze-thaw cycles, while it reduces with the increases of freeze-thaw cycles at the same strain rate. It is found that the 10 freeze-thaw cycles are an obvious inflection point. When it is less than 10 cycles, the dynamic compressive strength of sandstone specimens decreases rapidly, it is more than 10 cycles, and the strength decreases gradually. This is due to that the evolution progress of pores in sandstone is more uniform after a certain number of freeze-thaw cycles. Meantime, the effect of freezing and thawing is mostly restrained by the pore evolution. On the other hand, the dissipated energy required for sandstone failure grows up with the increase of the number of freeze-thaw cycles. It shows that more energy is needed for the engender of pores and fractures in sandstone caused by freeze-thaw cycle. This led to the deterioration of sandstone structural stability and the decrease of dynamic mechanical properties.
\end{abstract}

\section{Introduction}

More than $70 \%$ of the land area of China is perennially frozen and seasonally frozen. Among them, some areas in the northeast and high-altitude areas in the west are permafrost regions, while north and south China are seasonal permafrost regions [1]. These frozen regions are rich in mineral resources, and the rock mass will inevitably receive dynamic loads such as impact of drilling and blasting in the process of mineral mining. In addition, the effect of temperature change on rock freezing and thawing mechanics cannot be ignored [2]. Therefore, the study of mechanical properties and failure law of rock under the combined action of freeze-thaw and dynamic load is of great significance to rock mass engineering in frozen regions.

At present, the mechanical properties of rock under conventional freeze-thaw cycles have been deeply studied by many scholars [3-18]. Zhou et.al [19-21] used the NMR system to study the pore structure change and damage mecha- nism of granite under freeze-thaw cycle. Amitrano et.al [22] tested the failure characteristics of rock under the action of freeze-thaw cycle by acoustic emission test and found that a large number of internal cracks occurred with the progress of freeze-thaw cycle. Wu et.al [23] studied the longitudinal wave velocity, mass, and volume of marble after freezethaw cycle and summed up the physical and mechanical properties of marble after freeze-thaw cycle. Yang et.al [24] used uniaxial and triaxial compression tests of sandstone and coal under different temperatures and confining pressures to study the strength properties of rocks under freeze-thaw cycles. Nicholson et.al [25] carried out freezethaw cycle tests on fractured rocks to study the effect of primary fractures on the degree of freeze-thaw damage. Huseyin et.al [26] tested the compressive strength and other parameters of andesite after freeze-thaw cycle and obtained the deterioration law of andesite. Jihwan Park et.al [27] used CT scanning and SEM techniques to analyze the microstructure changes of rocks under freeze-thaw cycles. Bellanger 


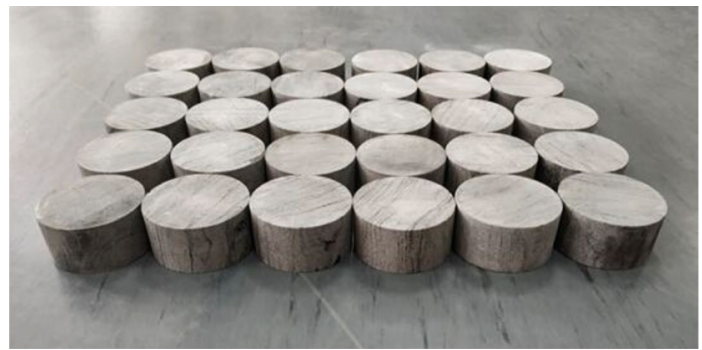

FIGURE 1: Sandstone samples under impact loading test.

TABLE 1: The basic mechanical parameters of the tested sandstone.

\begin{tabular}{lcccc}
\hline $\begin{array}{l}\text { Uniaxial compressive } \\
\text { strength/MPa }\end{array}$ & Longitudinal strain/10 & Tensile strength/MPa & Transverse strain/10 & Elastic modulus/GPa Poisson's ratio \\
\hline 28.05 & 0.84 & 3.91 & 0.09 & 3.82 \\
\hline
\end{tabular}

et.al [28] studied the saturated water content, porosity, and permeability of limestone in northeastern France and obtained the relationship between them.

Moreover, the internal damage and fracture process of rock under dynamic load will be accompanied by the transformation and dissipation of energy. Energy dissipation is the most important factor in rock failure; so, many scholars have made an indepth study on the mechanism of rock energy dissipation [29-32]. For instance, Xie et.al [33, 34] found that the internal damage and fracture of rock are caused by external energy, and the rock damage equation based on energy dissipation can better describe the damage process of rock. Gong et.al $[35,36]$ carried out static uniaxial compression test and Brazilian splitting test of red sandstone and found the law of linear energy storage and energy consumption in compression tension failure of rock.

However, the current research on the dynamic mechanical properties of rock under freeze-thaw is relatively few. In this paper, the dynamic uniaxial compression tests of sandstone under different freeze-thaw cycles are studied in detail, and its failure mechanism is analyzed from the point of view of energy.

\section{Samples and Test Methods}

2.1. Sample Making. The test samples are taken from sandstone with good particle uniformity and structural integrity in Baorixile open-pit mining area in Hulunbuir City, Inner Mongolia. According to the Standard of Experimental method for Engineering Rock Mass [37], the sandstone sample is polished into a disc sample with a height of $25 \mathrm{~mm}$ and a diameter of $50 \mathrm{~mm}$, as shown in Figure 1, and the basic mechanical parameters of the tested sandstone are shown in Table 1.

2.2. Test Equipment. TDS-300 freeze-thaw cycle test machine is used in the freeze-thaw cycle test, as shown in Figure 2. The temperature can be controlled by the device is $-40^{\circ} \mathrm{C}-90^{\circ} \mathrm{C}$, and the temperature fluctuation is $\pm 0.05^{\circ} \mathrm{C}$.

The impact load test of sandstone using the Split Hopkinson Pressure Bar test device (SHPB) is shown in

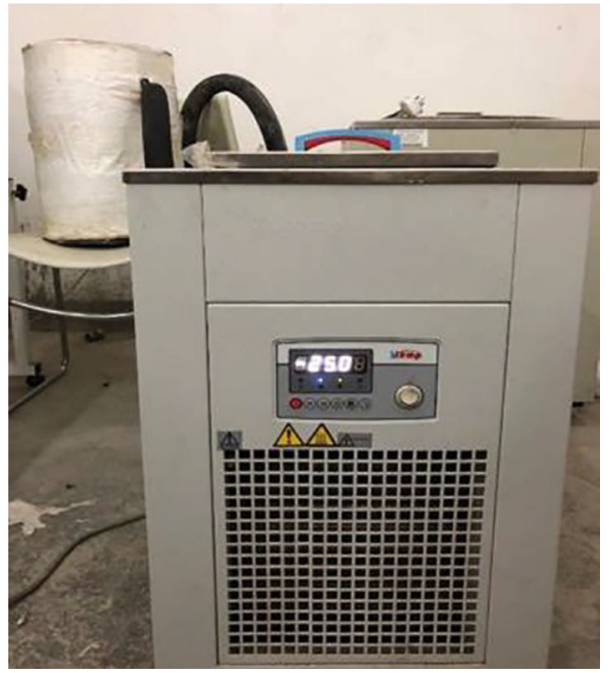

FIGURE 2: TDS-300 freeze-thaw cycle testing machine.

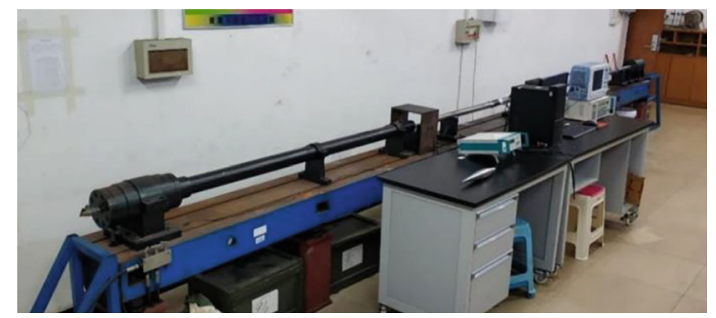

FIgure 3: Split Hopkinson Pressure Bar test device (SHPB).

Figure 3. The device can be used to test the impact dynamic characteristics of rock, concrete, and other materials. It is mainly composed of transmitting cavity, incident rod, transmission rod, and data acquisition and processing system. The rod is made of chromium alloy steel. The diameter of the incident rod and the transmission rod is $50 \mathrm{~mm}$, and the lengths are $2 \mathrm{~m}$ and $1.5 \mathrm{~m}$. 
TABLE 2: Bullet velocity and strain rate under different pressure.

\begin{tabular}{|c|c|c|c|c|c|}
\hline $\begin{array}{l}\text { Grouping and numbering } \\
\text { of samples }\end{array}$ & Air pressure $(\mathrm{MPa})$ & Bullet velocity (m/s) & Average speed $(\mathrm{m} / \mathrm{s})$ & Strain rate $\left(\mathrm{s}^{-1}\right)$ & Average strain rate $\left(\mathrm{s}^{-1}\right)$ \\
\hline $\mathrm{Y} 0-1$ & \multirow{6}{*}{0.5} & 11.25 & \multirow{6}{*}{11.03} & 54.8 & \multirow{6}{*}{53.15} \\
\hline Y1-1 & & 10.41 & & 50.2 & \\
\hline Y5-1 & & 11.09 & & 53.8 & \\
\hline Y10-1 & & 11.16 & & 51.7 & \\
\hline Y15-1 & & 11.27 & & 53.2 & \\
\hline Y20-1 & & 11.02 & & 55.2 & \\
\hline Y0-2 & \multirow{6}{*}{0.6} & 12.82 & \multirow{6}{*}{13.09} & 75.3 & \multirow{6}{*}{75.07} \\
\hline $\mathrm{Y} 1-2$ & & 12.98 & & 70.5 & \\
\hline Y5-2 & & 13.32 & & 73.8 & \\
\hline Y10-2 & & 12.93 & & 77.8 & \\
\hline Y15-2 & & 13.29 & & 77.7 & \\
\hline $\mathrm{Y} 20-2$ & & 13.19 & & 75.3 & \\
\hline Y0-3 & \multirow{6}{*}{0.7} & 14.41 & \multirow{6}{*}{14.92} & 98.9 & \multirow{6}{*}{99.07} \\
\hline $\mathrm{Y} 1-3$ & & 15.12 & & 102.6 & \\
\hline Y5-3 & & 14.77 & & 96.7 & \\
\hline Y10-3 & & 15.09 & & 96.1 & \\
\hline Y15-3 & & 14.84 & & 98.3 & \\
\hline Y20-3 & & 15.28 & & 101.8 & \\
\hline
\end{tabular}

TABle 3: Dynamic uniaxial compression mechanical parameters of sandstone under different freeze-thaw cycles.

\begin{tabular}{lccc}
\hline $\begin{array}{l}\text { Grouping and numbering } \\
\text { of samples }\end{array}$ & Strain rate $\left(\mathrm{s}^{-1}\right)$ & Compression strength $(\mathrm{MPa})$ & Axial strain $\left(10^{-2}\right)$ \\
\hline Y0-1 & 54.8 & 155.54 & 0.73 \\
Y0-2 & 75.3 & 179.11 & 0.97 \\
Y0-3 & 98.9 & 221.03 & 1.18 \\
Y1-1 & 50.2 & 140.28 & 0.87 \\
Y1-2 & 70.5 & 167.99 & 1.04 \\
Y1-3 & 102.6 & 200.36 & 1.27 \\
Y5-1 & 53.8 & 130.46 & 0.98 \\
Y5-2 & 73.8 & 157.33 & 1.16 \\
Y5-3 & 96.7 & 185.65 & 1.36 \\
Y10-1 & 51.7 & 121.75 & 1.09 \\
Y10-2 & 77.8 & 148.94 & 1.28 \\
Y10-3 & 96.1 & 176.21 & 1.44 \\
Y15-1 & 53.2 & 112.23 & 1.16 \\
Y15-2 & 77.7 & 140.07 & 1.33 \\
Y15-3 & 98.3 & 166.83 & 1.52 \\
Y20-1 & 55.2 & 105.28 & 1.21 \\
Y20-2 & 75.3 & 135.68 & 1.39 \\
Y20-3 & 101.8 & 158.76 & 1.59 \\
\hline
\end{tabular}

2.3. Test Scheme and Process. First of all, the sandstone samples were saturated with water, and after the samples were completely saturated, the freeze-thaw cycle test was carried out, and the single freeze-thaw cycle was set to $12 \mathrm{~h}$. The samples were frozen at $-20^{\circ} \mathrm{C}$ for $6 \mathrm{~h}$ and thawed at $20^{\circ} \mathrm{C}$ for $6 \mathrm{~h}$. The experiment was divided into 6 groups according to differ- ent freeze-thaw cycles, and the freeze-thaw times were $0,1,5$, 10, 15, and 20 times. After different freeze-thaw cycles, the Split Hopkinson Pressure Bar device was used to carry out impact loading tests on the samples with different impact pressures of $0.5 \mathrm{MPa}, 0.6 \mathrm{MPa}$, and $0.7 \mathrm{MPa}$, and the dynamic characteristics of sandstone samples were tested. 


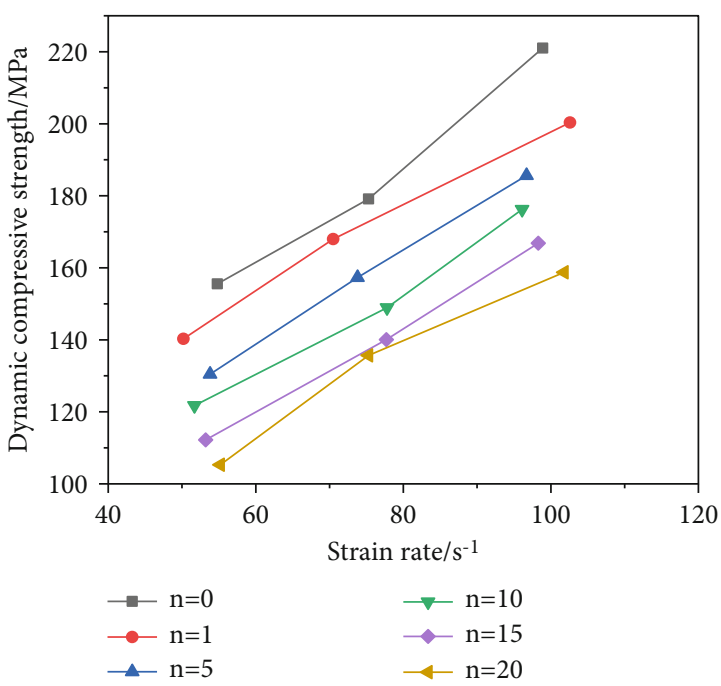

Figure 4: Dynamic compressive strength of sandstone under different strain rates.

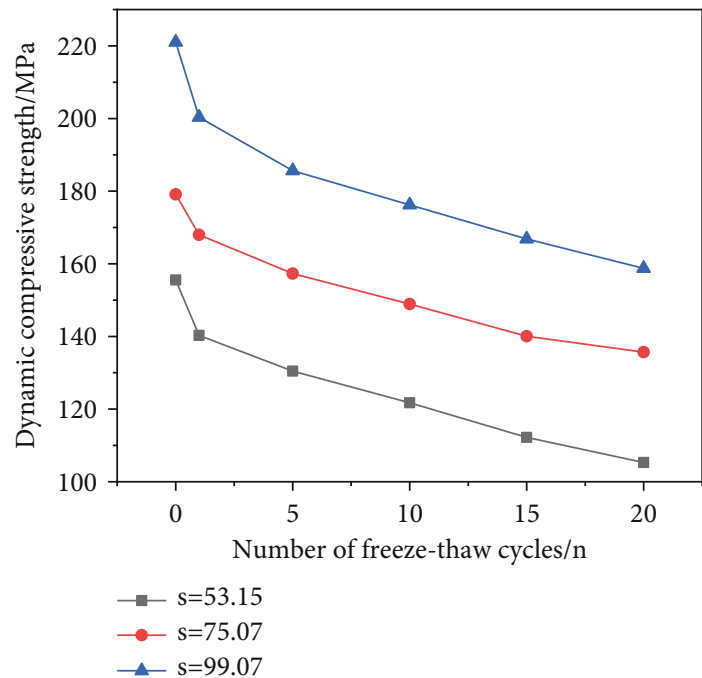

Figure 5: Dynamic compressive strength of sandstone under different freeze-thaw cycles.

\section{Test Results}

The bullet velocity and strain rate of uniaxial compression test under different impact pressure are shown in Table 2, and the peak dynamic compressive strength and peak strain of sandstone under different freeze-thaw cycles and strain rates are shown in Table 3.

3.1. Dynamic Uniaxial Compression Strength Analysis. The influence of strain rate and freeze-thaw cycles on dynamic compressive strength is as follows. Figure 4 shows the dynamic compression strength curve of sandstone under different strain rates, and $n$ is the number of freeze-thaw cycles. Figure 5 is the dynamic compression strength curve of sandstone under different freeze-thaw cycles, and $s$ is the strain rate.

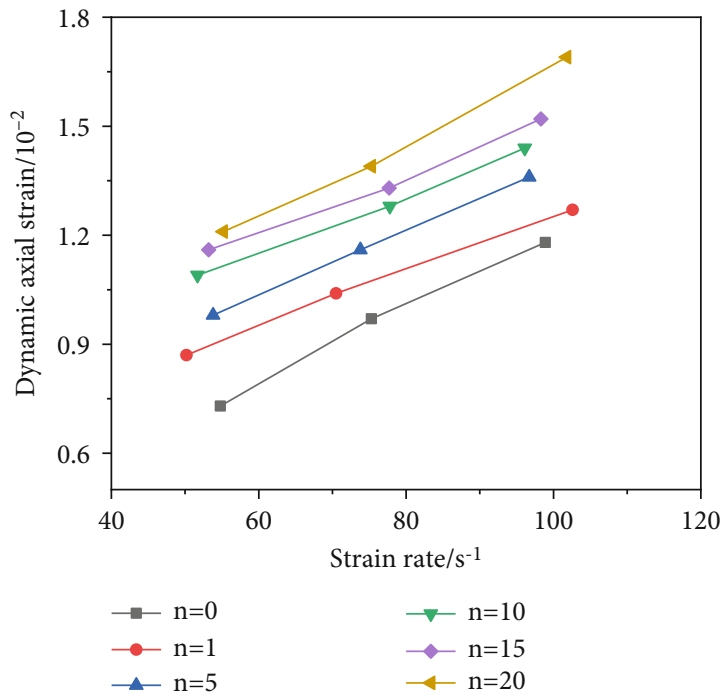

FIgURE 6: Dynamic axial strain of sandstone under different strain rates.

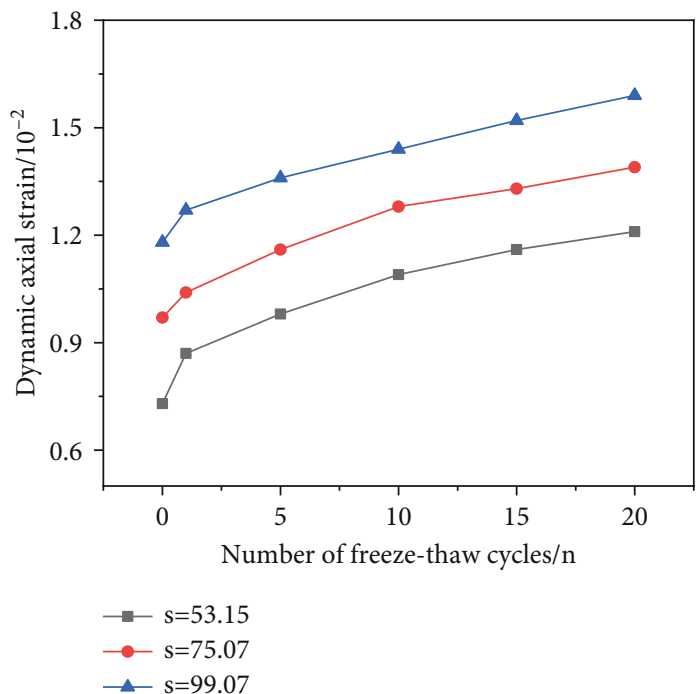

Figure 7: Dynamic axial strain of sandstone under different freezethaw cycles.

As shown in Figure 4, the dynamic compressive strength of sandstone rises with the increase of strain rate. This is due to that under the impact load of high strain rate, the sandstone with the same number of freeze-thaw cycles needs more stress, which leads to the failure of sandstone samples. The compressive strength declines with the increase of freeze-thaw cycles. It is clear that both strain rate and freeze-thaw affect the dynamic compressive strength of sandstone, but the effect of freeze-thaw is higher than that of strain rate.

As illustrated in Figure 5, the dynamic compressive strength of sandstone declines with the increase of freezethaw cycles. The reason is that repeated freeze-thaw cycles lead to repeated expansion and contraction of pores in sandstone, resulting in pores gradually developing into cracks and seriously destroying the internal structure of sandstone; 
TABLE 4: Energy statistical table.

\begin{tabular}{|c|c|c|c|c|c|}
\hline Sample number & Strain rate $/ \mathrm{s}^{-1}$ & $W_{I} / J$ & $W_{R} / \mathrm{J}$ & $W_{T} / \mathrm{J}$ & $W_{S} / \mathrm{J}$ \\
\hline Y0-1 & 54.8 & 126.38 & 39.10 & 36.78 & 50.5 \\
\hline Y0-2 & 75.3 & 179.07 & 61.01 & 59.92 & 58.14 \\
\hline Y0-3 & 98.9 & 230.24 & 86.51 & 54.51 & 89.22 \\
\hline Y1-1 & 50.2 & 127.30 & 37.92 & 36.02 & 53.36 \\
\hline Y1-2 & 70.5 & 178.84 & 58.64 & 47.34 & 72.86 \\
\hline Y1-3 & 102.6 & 233.03 & 88.62 & 44.36 & 100.05 \\
\hline Y5-1 & 53.8 & 126.84 & 38.86 & 34.17 & 53.81 \\
\hline Y5-2 & 73.8 & 180.14 & 58.62 & 45.68 & 75.84 \\
\hline Y5-3 & 96.7 & 230.17 & 80.27 & 32.80 & 117.1 \\
\hline Y10-1 & 51.7 & 127.99 & 37.44 & 31.41 & 59.14 \\
\hline Y10-2 & 77.8 & 180.37 & 62.14 & 35.76 & 82.47 \\
\hline Y10-3 & 96.1 & 232.27 & 85.79 & 31.87 & 114.61 \\
\hline Y15-1 & 53.2 & 126.95 & 38.69 & 28.01 & 60.25 \\
\hline Y15-2 & 77.7 & 180.28 & 60.25 & 32.40 & 87.63 \\
\hline Y15-3 & 98.3 & 230.81 & 81.22 & 30.12 & 119.47 \\
\hline Y20-1 & 55.2 & 126.33 & 37.53 & 28.12 & 60.68 \\
\hline Y20-2 & 75.3 & 179.72 & 59.42 & 31.84 & 88.46 \\
\hline Y20-3 & 101.8 & 231.45 & 83.18 & 28.86 & 119.41 \\
\hline
\end{tabular}

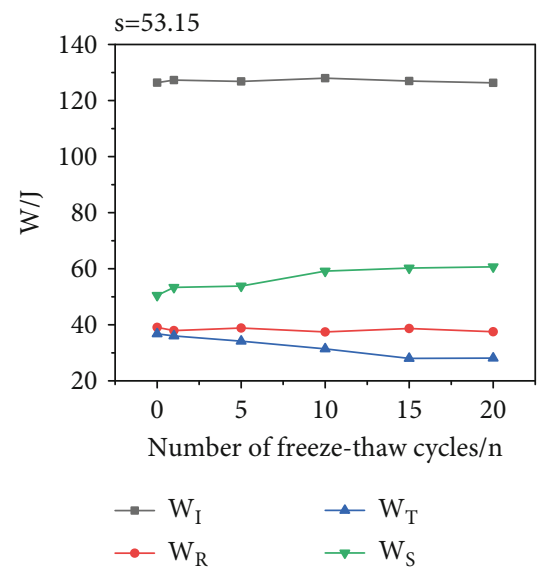

(a) $s=53.15$

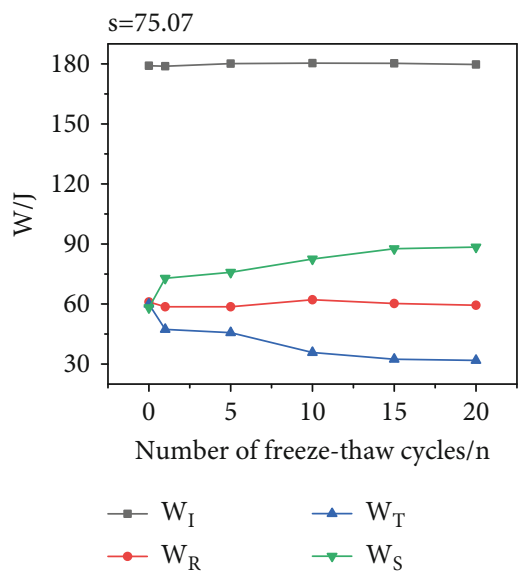

(b) $s=75.07$

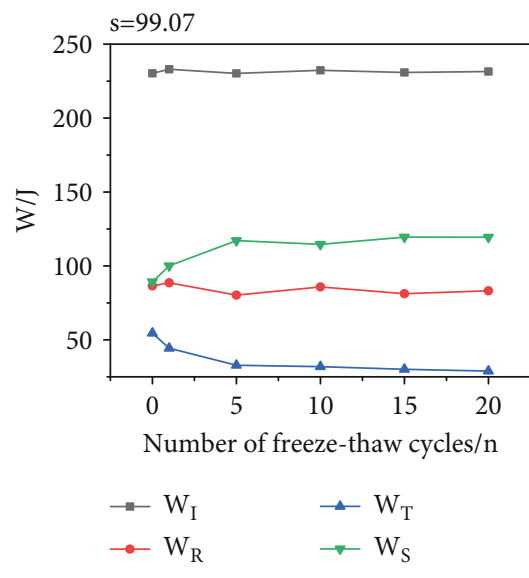

(c) $s=99.07$

FIGURE 8: Four kinds of energy change curves under different strain rates and freeze-thaw cycles.

so, freeze-thaw cycles will significantly reduce the mechanical properties of sandstone.

3.2. Variation Law of Dynamic Axial Strain. The effect of strain rate and freeze-thaw cycle on strain: Figure 6 shows the dynamic axial strain curve of sandstone under different strain rates. Figure 7 shows the dynamic axial strain curve of sandstone under different freeze-thaw cycles.

As it can be seen from Figure 6: the dynamic axial strain of sandstone growth with the increase of strain rate, the reason is that the higher stress is needed to destroy the sandstone sample at high strain rate; so, the axial strain increases.
In Figure 7, the axial strain of sandstone ascends with the increase of freeze-thaw cycles. This is due to those different times of freeze-thaw cycles will destroy the internal structure of sandstone and make the internal pores growth into through fissures, resulting in the axial strain of sandstone samples will rise with the increase of the number of freezethaw cycles.

\section{Discussion}

4.1. Energy Dissipation Law. In the impact load test of sandstone, the destruction process of sandstone must be accompanied by the absorption and dissipation of energy. Energy 


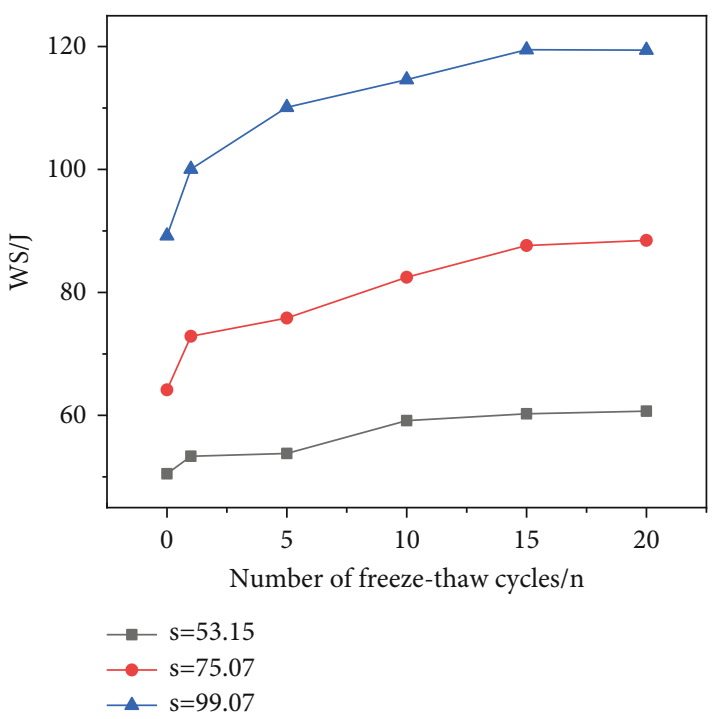

Figure 9: The variation curve of dissipative energy with the number of freeze-thaw cycles under different strain rates.

absorption in sandstone depends on factors such as pore space. The development and expansion of pores and fractures within the sandstone require the absorption of energy [21]. The dissipated energy required for sandstone failure can be calculated by incident energy, reflection energy, and transmission energy. The formula is as follows:

$$
\begin{gathered}
W_{I}=E_{o} C_{o} A_{o} \int_{o}^{t} \varepsilon_{I}^{2}(t) d t, \\
W_{R}=E_{o} C_{o} A_{o} \int_{o}^{t} \varepsilon_{R}^{2}(t) d t, \\
W_{T}=E_{o} C_{o} A_{o} \int_{o}^{t} \varepsilon_{T}^{2}(t) d t .
\end{gathered}
$$

In the formula, $W_{I}$ is the incident energy, $W_{R}$ is the reflected energy, $W_{T}$ is the transmission energy, $E_{o}$ is the elastic modulus of rod, $C_{o}$ is the longitudinal wave velocity of the rod, $A_{o}$ is the cross-sectional area of the rod, $\varepsilon_{t}(\mathrm{t})$ is the incident stress wave strain signal, $\varepsilon_{R}(\mathrm{t})$ is the reflected stress wave strain signal, and $\varepsilon_{T}(\mathrm{t})$ is the transmitted stress wave strain signal.

The dissipated energy in the failure process of sandstone specimen is expressed by $W_{S}$, and the formula is

$$
W_{S}=W_{I}-W_{R}-W_{T} .
$$

Table 4 shows the energy statistics of dynamic uniaxial compression test of sandstone under different freeze-thaw cycles.

Figure 8 shows the variation curve of four kinds of energy with the number of freeze-thaw cycles when the average strain rates are 53.15, 75.07, and 99.07. It can be seen from Figure 8 that the incident energy and transmission energy remain stable under different freeze-thaw cycles.
However, the incident energy and transmission energy grow up with the increase of strain rate, and the higher the strain rate, the greater their growth. It shows that the incident energy and reflection energy are not sensitive to the number of freeze-thaw cycles. The transmission energy reduces with the increase of freeze-thaw cycles and increases at first and then declines with the increase of strain rate. The dissipated energy ascends with the increase of the number of freezethaw cycles, and the higher the strain rate, the greater the increase of dissipative energy.

4.2. Failure Mechanism of Sandstone Sample. The strain rate effect of dynamic compressive strength of sandstone is analyzed from the point of view of energy. The interior of the sandstone sample is full of natural pores and fissures, and the failure process of sandstone is also the process of the development and expansion of pores and fissures. The crack rises with the increase of strain rate and so does the energy require [38]. Because the time of impact load is very short, the sample can only increase the stress to balance the external energy; so, the dynamic compressive strength of sandstone samples ascends with the increase of strain rate.

Figure 9 shows the curve of dissipated energy varying with the number of freeze-thaw cycles at different strain rates. It can be seen that the dissipated energy of sandstone sample rises obviously with the increase of the number of freeze-thaw cycles, and the growth rate of dissipative energy gains in with the increase of strain rate. It shows that the failure of sandstone under the combined action of freeze-thaw cycle and high strain rate impact load will absorb more energy and illustraion of the development of pores and cracks in sandstone needs higher energy. Therefore, with the increase of strain rate and the number of freeze-thaw cycles, the failure degree of sandstone specimens becomes larger and larger, as shown in Figure 10. 


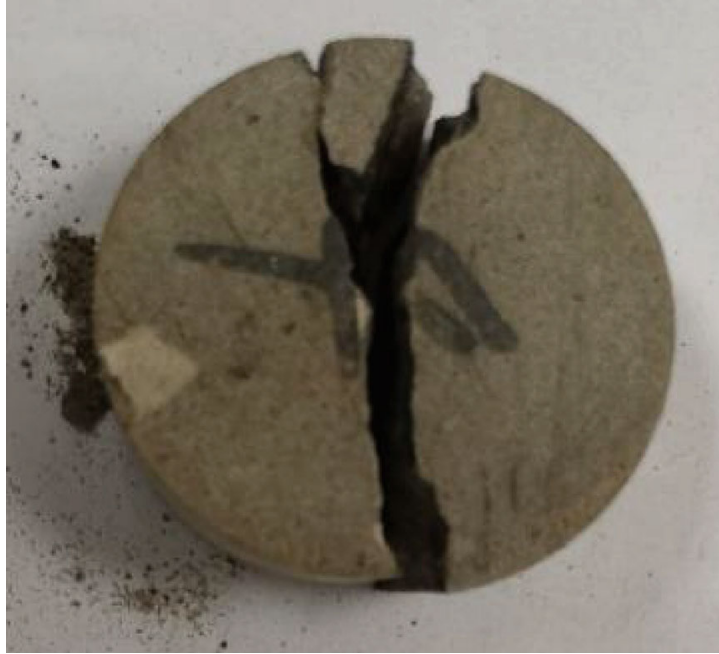

(a) $n=0$

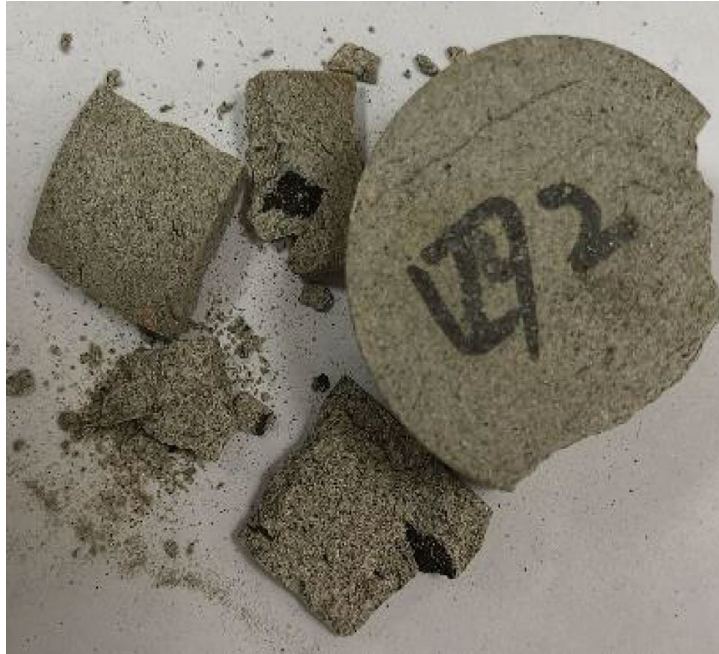

(c) $s=53.15$

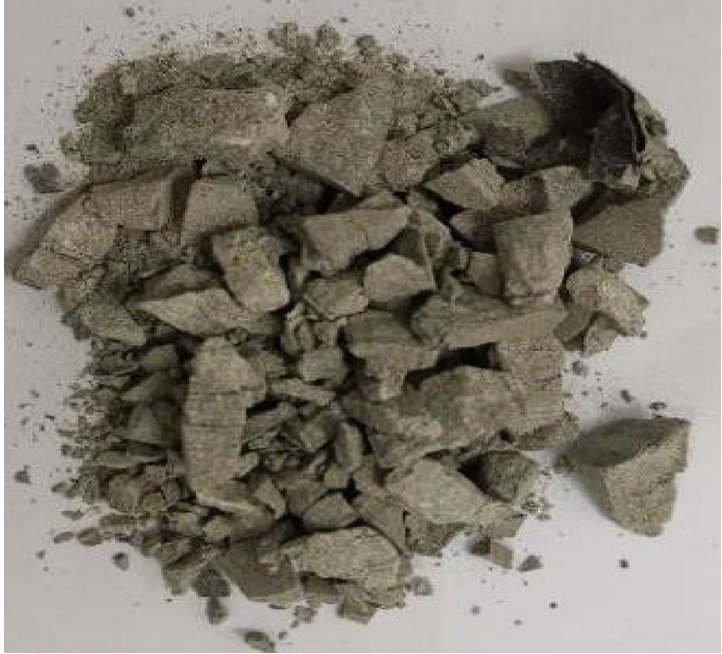

(b) $n=20$

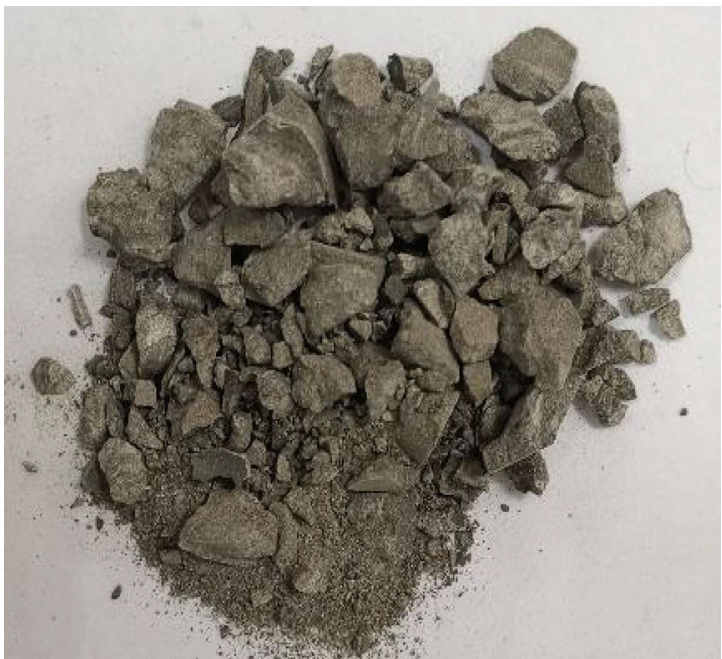

(d) $s=99.07$

FIGURE 10: Failure morphology of sandstone specimens under different freeze-thaw cycles and strain rates.

\section{Conclusions}

(1) The dynamic mechanical properties of sandstone are significantly affected by freeze-thaw cycles and strain rate. With the increase of freeze-thaw cycles, the strength of sandstone decreases and the strain increases and the strength and strain of sandstone growth with the increase of strain rate

(2) When the number of cycles is less than 10, the dynamic compressive strength of sandstone decreases rapidly, and the image is obviously concave. When the number of cycles is more than 10 times, the strength decreases gradually, and the image shows a convex shape. 10 freeze-thaw cycles are an obvious inflection point. The reason is that after a certain number of freeze-thaw cycles, the internal pores of sandstone develop more evenly, which suppresses the effect of freeze-thaw on sandstone and slows the decrease of strength
(3) With the increase of the number of freeze-thaw cycles, the dissipative energy is required for sandstone failure growth. The reason is that the freezethaw cycle makes the sandstone loose, and the development of cracks aggravates. When the sandstone is destroyed by external forces, it is easy to produce more cracks, resulting in a greater degree of failure of the samples, showing a powder clastic shape

\section{Data Availability}

The data that support the findings of this study are available from the corresponding author, upon reasonable request.

\section{Conflicts of Interest}

The authors declare no conflict of interest. 


\section{Acknowledgments}

Thank you for the review experts for their comments on this article. At the same time, thanks for all those who are helpful to this experiment. This work was supported by the National Natural Science Foundation of China [Grant Nos. 51522903, 51774184], Excellent Project Fund in North China University of Technology [Grant No. 216051360020XN199/006], and Scientific Research Fund in North China University of Technology [Grant No. 110051360002].

\section{References}

[1] Y. Yang, "Experimental study on dynamic mechanical properties of rock under low temperature," China University of mining and Technology (Beijing), 2016.

[2] G. M. Xu and Q. S. Liu, "Analysis of freeze-thaw failure mechanism of rock and experimental study of freeze-thaw mechanics," Acta rock mechanics and engineering, vol. 24, no. 17, pp. 3076-3082, 2005.

[3] J. R. Ma and G. S. Yang, "Preliminary study on water thermal mechanical coupling of freeze-thaw damage of soft rock," Journal of rock mechanics and engineering, vol. 25, no. z1, pp. 4373-4377, 2004.

[4] D. M. Lang and T. C. Li, "Energy evolution and damage ontology of rocks under freeze-thaw cycles," Mining Research and Development, vol. 40, no. 4, pp. 74-78, 2020.

[5] N. Liu, Mechanical Experiment and Hydro Thermal Coupling Analysis of Rock Freezing and Thawing, Xi'an University of science and technology, 2010.

[6] G. Q. Chen, Y. Wan, X. Sun, and G. Z. Zhang, "Research on the effect of temperature range on the creep behaviour of sandstone subjected to freeze-thaw cycles and its fractional order damage model," Chinese Journal of Rock Mechanics and Engineering, pp. 1-14, 2021.

[7] Y. Wang, B. Zhang, B. Li, and C. H. Li, “A strain-based fatigue damage model for naturally fractured marble subjected to freeze-thaw and uniaxial cyclic loads," International Journal of Damage Mechanics, vol. 30, no. 10, pp. 1594-1616.

[8] L. Zhang, "On mechanical properties and failure characteristics of surrounding rock of tunnel with weak interlayer under freeze-thaw cycles," Hydrogeology \& Engineering Geology, pp. $1-7,2021$.

[9] Y. Wang, Y. F. Yi, C. H. Li, and J. Q. Han, "Anisotropic fracture and energy characteristics of a Tibet marble exposed to multi-level constant-amplitude (MLCA) cyclic loads: a labscale testing," Engineering Fracture Mechanics, vol. 244, p. 107550, 2021.

[10] J. Zhang, R. Xu, Y. Liu, H. Zhang, X. Tan, and M. Chen, "Experimental study on mechanical properties of grouted fractured rock under the action of freeze-thaw cycles," Journal of Experimental Mechanics, vol. 36, no. 3, pp. 378-388, 2021.

[11] S. A. Ghoreishi-Madiseh, F. Hassani, A. Mohammadian, and F. Abbasy, "Numerical modeling of thawing in frozen rocks of underground mines caused by backfilling," International Journal of Rock Mechanics \& Mining Sciences, vol. 48, no. 7, pp. 1068-1076, 2011.

[12] S. Chang, J. Y. Xu, and G. H. Zheng, "Study on strain rate characteristics of frozen-thawed bedding sandstone under impact load," Chinese Journal of Underground Space and Engineering, vol. 17, no. 1, pp. 53-61, 2021.
[13] H. Liao, Y. Chen, S. Li, Y. Yin, C. Peng, and Z. Li, "Mechanical properties of sandstone under freeze-thaw cycling and chemical corrosion," Journal of Disaster Prevention and Mitigation Engineering, vol. 40, no. 6, pp. 1009-1017, 2020.

[14] L. N. Wang, X. M. Yi, J. Han, and J. Z. Wang, "Strength degradation and forecast model of siltstone under combined effect of chemical solutions and freeze-thaw cycles," Journal of Central South University (Science and Technology), vol. 51, no. 8, pp. 2361-2372, 2020.

[15] J. J. Zhao, M. L. Xie, J. L. Yu, and W. H. Zhao, "Experimental study on mechanical properties and damage evolution of fractured rock under freeze-thawing action," Journal of Engineering Geology, vol. 27, no. 6, pp. 1199-1207, 2019.

[16] Y. Hou, X. Zhang, P. Li, P. Ding, S. Cao, and D. Han, “Mechanical properties and non-destructive testing of cemented mass of unclassified tailings under freeze-thaw cycles," Chinese Journal of Engineering, vol. 41, no. 11, p. 1443, 2019.

[17] H. M. Zhang, X. Z. Meng, C. Peng et al., "Rock damage constitutive model based on residual intensity characteristics under freeze-thaw and load," Journal of China Coal Society, vol. 44, no. 11, pp. 3404-3411, 2019.

[18] X. Zhang and C. A. Yanyan, "Meso-damage and mechanical properties degradation of sandstone under combined effect of water chemical corrosion and freeze-thaw cycles," Rock and Soil Mechanics, vol. 40, no. 2, pp. 455-464, 2019.

[19] K. Zhou, J. Li, Y. Xu, Y. Zhang, P. Yang, and L. Chen, “Experimental study on nuclear magnetic resonance characteristics of rocks under freeze-thaw cycles," Journal of rock mechanics and engineering, vol. 31, no. 4, pp. 731-737, 2012.

[20] Y. J. Xu, K. P. Zhou, and J. L. Li, “Z Y M. nuclear magnetic resonance detection of freeze-thaw rock and analysis of freezethaw damage mechanism," Geotechnical mechanics, vol. 33, no. 10, pp. 3001-3006, 2012.

[21] B. Ke, K. Zhou, H. Deng, and F. Bin, "NMR pore structure and dynamic characteristics of sandstone caused by ambient freezethaw action," Shock and Vibration, vol. 2017, 10 pages, 2017.

[22] D. Amitrano, S. Gruber, and L. Girard, "Evidence of frostcracking inferred from acoustic emissions in a high-alpine rock-wall," Earth and Planetary Science Letters, vol. 341-344, pp. 86-93, 2012.

[23] G. Wu, G. L. He, L. Zhang, and Y. P. Qiu, "Experimental study on cyclic freeze-thaw of marble," Journal of rock mechanics and engineering, vol. S1, pp. 2930-2938, 2006.

[24] G. Yang, J. Xi, X. Shao, H. Li, and L. Cheng, "Experimental study on rock strength characteristics under freezing conditions," Journal of Xi'an University of science and technology, vol. 30, no. 1, pp. 14-18, 2010.

[25] D. T. Nicholson and F. H. Nicholson, "Physical deterioration of sedimentary rocks subjected to experimental freeze-thaw weathering," Earth Surface Processes and Landforms, vol. 25, no. 12, pp. 1295-1307, 2000.

[26] Y. Huseyin, "Effect of freeze-thaw and thermal shock weathering on the physical and mechanical properties of an andesite stone," Bulletin of Engineering Geology and the Environment, vol. 70, no. 2, pp. 187-192, 2011.

[27] J. Park, C. U. Hyun, and H. D. Park, "Changes in microstructure and physical properties of rocks caused by artificial freeze-thaw action," Bulletin of Engineering Geology and the Environment, vol. 74, no. 2, pp. 555-565, 2015.

[28] M. Bellanger, F. Homand, and J. M. Remy, "Water behaviour in limestones as a function of pores structure: application to 
frost resistance of some Lorraine limestones," Engineering Geology, vol. 36, no. 1-2, pp. 99-108, 1993.

[29] Y. Bernabé and A. Revil, "Pore-scale heterogeneity, energy dissipation and the transport properties of rocks," Geophysical Research Letters, vol. 22, no. 12, pp. 1529-1532, 1995.

[30] V. Sujatha and J. M. C. Kishen, "Energy release rate due to friction at bimaterial interface in dams," Journal of Engineering Mechanics, vol. 129, no. 7, pp. 793-800, 2003.

[31] Y. Ju, H. J. Wang, Y. M. Yang, Q. A. Hu, and R. D. Peng, "Numerical simulation of mechanisms of deformation, failure and energy dissipation in porous rock media subjected to wave stresses," SCIENCE CHINA Technological Sciences, vol. 53, no. 4, pp. 1098-1113, 2010.

[32] R. Peng, Y. Ju, J. G. Wang, H. Xie, F. Gao, and L. Mao, “Energy dissipation and release during coal failure under conventional triaxial compression," Rock Mechanics and Rock Engineering, vol. 48, no. 2, pp. 509-526, 2015.

[33] H. Xie, L. Li, R. Peng, and Y. Ju, "Energy analysis and criteria for structural failure of rocks," Journal of Rock Mechanics and Geotechnical Engineering, vol. 1, no. 1, pp. 11-20, 2009.

[34] H. Xie, L. Li, Y. Ju, R. Peng, and Y. Yang, "Energy analysis for damage and catastrophic failure of rocks," Science China Technological Sciences, vol. 54, no. 1, pp. 199-209, 2011.

[35] F. Q. Gong, J. Y. Yan, and X. B. Li, “A new criterion of rock burst proneness based on the linear energy storage law and the residual elastic energy index," Chinese Journal of Rock Mechanics and Engineering, vol. 37, no. 9, pp. 1993-2014, 2018.

[36] F. Q. Gong, S. Luo, X. B. Li, and J. Y. Yan, "Linear energy storage and dissipation rule of red sandstone materials during the tensile failure process," Chinese Journal of Rock Mechanics and Engineering, vol. 37, no. 2, pp. 352-363, 2018.

[37] Standard of Experimental method for Engineering Rock MassGB/T 50266-1999.

[38] J. Liu, J. Xu, X. Lu, L. Zhang, and Z. Wang, "Experimental study on dynamic mechanical properties of Amphibolite's under impact compressive loading," Chinese Journal of Rock Mechanics and Engineering, vol. 28, no. 10, pp. 2113-2121, 2009. 